\title{
Ab ins Netz!
}

_ Sind Sie schon einmal auf unserer Homepage vorbeigesurft? Nein? Dann wird es höchste Zeit! Denn auf www.thieme.de/ergoonline bieten wir Ihnen ein breites Spektrum an neuesten Informationen rund um Fachbücher, Veranstaltungen, Termine, Assessments - und natürlich rund um die ergopraxis!

_ Zu jeder Ausgabe stellen wir Ihnen zusätzliche Informationen zur Verfügung. Zum Beispiel Dokumentationsbögen, Behandlungsansätze, Tabellen oder Gesetzestexte. Die Literaturverzeichnisse haben wir auf unsere Homepage ausgelagert, damit im Heft mehr Platz für die Inhalte bleibt. Unsere Zusatzinformationen sind offen für alle Interessierten!

_ Per Mausklick erhalten Sie unsere Artikel exklusiv im pdf-Format. So können Sie Ihre Lieblingsthemen platzsparend und staubfrei digital archivieren und müssen nicht alle Hefte aufheben. Zusätzlich gibt's ein Jahresregister zum Herunterladen. So behalten Sie alle bereits erschienenen Themen im Blick. www-Tipps vervollständigen unser Internetangebot.

_ Wenn Sie nach einer bestimmten Fortbildung in Ihrer Nähe suchen, dann sollten Sie in unserer Fobibörse auf www.fobiboerse.de vorbeischauen. Dort können Sie gezielt nach freien Plätzen stöbern und sich spontan dazugesellen.

Viel Spaß beim sommerlichen Surfen in der Winterzeit wünscht Ihnen Ihre

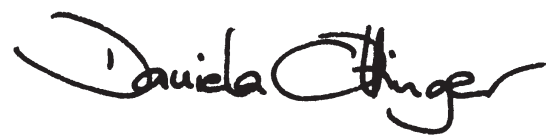

PS: Melden Sie sich bei www.thieme.de/ergoonline auch für unseren Newsletter an! Wir versorgen Sie einmal im Monat mit Neuigkeiten aus der Ergowelt - damit Sie immer am Puls der Zeit bleiben! 